\title{
Enfermedad, transgresión y subjetividad en el México contemporáneo Presentación
}

\author{
Cristina Sacristán \\ (D) http://orcid.org/0000-0002-9587-7096 \\ Instituto de Investigaciones Dr. José María Luis Mora, México. \\ csacristan@institutomora.edu.mx
}

\section{María Eugenia Chaoul \\ (D) http://orcid.org/0000-0002-9421-5023 \\ Instituto de Investigaciones Dr. José María Luis Mora, México. \\ mchaoul@institutomora.edu.mx}

$\mathrm{U}$ na amplia discusión teórica sobre la construcción del sujeto y la subjetividad ha ocupado el trabajo de sociólogos, antropólogos e historiadores desde décadas atrás. El interés por rescatar, recuperar y darle visibilidad al sujeto se presentó como una respuesta al armazón determinista del estructuralismo marxista de los años setenta, como resultado de la volatilización de las relaciones sociales con la globalización del capitalismo en los últimos tiempos y en relación con la percepción, desde los movimientos sociales, que las estructuras políticas y culturales parecían menos sólidas y determinantes de lo que se suponía (Sewell, 2005, p. 59).

Desde la teoría social, el sujeto dejó de ser visto como un engrane funcional de un sistema autorregulable para adquirir el papel de agente. Específicamente, las teorías de la práctica social destacaron el poder que tienen los seres humanos y su capacidad transformadora dispuesta para intervenir en un conjunto dado de eventos y, de alguna manera, alterarlos (Giddens,

Cómo citAR: Sacristán, C. y Chaoul, M. E. (2019). Enfermedad, transgresión y subjetividad en el México contemporáneo. Presentación. Secuencia (104), e1740. DoI: https://doi.org/10.18234/secuencia.v0i104.1740

CC 1 Esta obra está protegida bajo una Licencia Creative Commons Atribución-NoComercial 4.0 Internacional. 
1987; Scott, 2000). El sujeto actuante también se entendió como productor de significados derivados de la interacción con otros actores y dentro de una estructura, campo, habitus o configuración (Ortner, 2006).

Los teóricos de la acción social vislumbraron un espacio posible de "maniobra" en relación con las estructuras. Si bien entre ellos difieren en el grado de autonomía otorgado, el sujeto se afirma como parte constitutiva del cambio o de la permanencia. A veces la autonomía se caracteriza, como en el caso de Giddens y Scott, por una relación dialéctica, que toma en cuenta tanto la mediación institucional como la capacidad de respuesta y la negociación o la resistencia del agente; en otras, la capacidad de autonomía es menor pues las estructuras han sido interiorizadas como plantea Bourdieu.

Frente a las categorías estáticas que presentaba el marxismo estructuralista, los historiadores también llevaron a la mesa de discusión la dinámica de la actuación de los sujetos históricos. E. P. Thompson, por ejemplo, propuso que la experiencia estaba relacionada con las respuestas mentales y emocionales de los grupos o del individuo frente a la pluralidad de acontecimientos. Los cambios, o bien la duración de los procesos, a partir de este enfoque, dan lugar a experiencias transformadoras en los individuos, a la vez que detonan la actuación sobre la estructura existente (Thompson, 1981).

La concepción de un actor que experimenta y es capaz de tener influencia en el cambio o ser consciente de su subjetividad, fue fuertemente criticada por Michel Foucault. El sujeto pasó a ser un actor disciplinado y modelado a través del poder. La subjetivación quedó reducida al sometimiento a partir de tecnologías disciplinarias y discursos normalizadores. El cuerpo se entendió como otra extensión del biopoder y como un objeto que podía ser manipulado y controlado. No obstante, en este callejón sin salida, el propio Foucault abrió un espacio, en un segundo momento de su trabajo, para explorar la subjetividad al tratar de entender cómo el sujeto cuida de sí en diferentes contextos institucionales y los procedimientos o técnicas del yo que utiliza para construir su identidad.

La incorporación de la cultura desde una visión fluida, cambiante y globalizada ha llevado a un replanteamiento teórico en torno a la experiencia y la formación de la subjetividad. Sin embargo, falta pensar y repensar en muchos temas y líneas de análisis para abordar el proceso de significación de nuestras vivencias personales y colectivas. La subjetividad de los actores - tales como las formas en que asumen su experiencia, cómo se reconocen a sí mismos y cómo forman sus decisiones; cómo dan significado a su actuación y cómo in- 
terpretan sus identidades-, entre otros cuestionamientos, es el tema que nos ocupa en este dossier y que se analiza desde la enfermedad y la transgresión, tópicos que atañen a la salud física, social y moral de las poblaciones, ya que trascienden el hecho biológico y el meramente normativo por su impacto en aspectos como la emergencia de saberes especializados, la creación de instituciones bajo una decidida intervención del Estado, la configuración del lugar del experto o la medicalización de conductas sociales. Ello ha conducido al estudio de las regulaciones y las sanciones normativas, las acciones destinadas a prevenir y combatir la enfermedad y el delito, y los procesos de profesionalización y legitimación de aquellos conocimientos que, como la medicina, la criminología, la psicología o la pedagogía, han pretendido normar desde una posición científica a grandes colectivos. De igual modo, se han examinado los instrumentos de control y disciplinamiento dirigidos a los individuos y sus cuerpos, que comprenden instituciones, sistemas teóricos y prácticas asistenciales encaminadas a la reducción o el aislamiento de los elementos nocivos para la sociedad o transgresores de la norma (Armus, 2000).

Con este dossier esperamos contribuir a recuperar a los sujetos que han sido y son objeto de tales intervenciones desde la perspectiva de su propia subjetividad, experiencia íntima que habría detonado con el correr del siglo xVIII, el cual produjo una conciencia individualista que se expresó en una subjetividad cada vez más secularizada, una división entre la esfera pública y la privada, y un conjunto de prácticas destinadas a la introspección como la redacción de cartas, diarios o autobiografías, narrativas escritas desde el yo. Ello abonó al cultivo de las ciencias de la mente y, sobre todo, del discurso psicológico para comprender la experiencia humana. La irrupción del psicoanálisis $y$, posteriormente, de todo tipo de técnicas de autoconocimiento, contribuyeron aún más a condicionar la forma en que los individuos se veían a sí mismos, se autocuidaban y se proyectaban frente a los otros. Por ello, el estudio de la subjetividad no puede ser más pertinente, tanto en su genealogía como en su despliegue actual (Novella, 2013).

De acuerdo con esta postura, el presente dossier de Secuencia reúne cuatro artículos de reconocidos investigadores que acudieron al llamado de la convocatoria para acercarse a la experiencia de la subjetividad en el mundo contemporáneo desde una perspectiva histórica y sociológica. El dossier aborda de manera muy original las subjetividades masculinas en contextos de violencia hacia las mujeres (Santillán Esqueda y Maya González), pero también bajo condiciones de padecimientos incurables en las primeras décadas del 
siglo xx como la sífilis (García Peña), y se aproxima al mundo interior de un asesino con trastornos de personalidad mediante el recurso del psicoanálisis, un método que descubre los significados inconscientes de los actos (Maya González). Las subjetividades femeninas también cobran presencia a través de las experiencias del parto por cesárea no planeada (Márquez Murrieta) y del matrimonio convenido con fines no reproductivos, que desemboca en un desarrollo profesional inesperado (García Peña), y todo ello, en el marco de las políticas de salud, discursos de la biomedicina y mandatos de género en el México contemporáneo, de la revolución a nuestros días.

Desde la perspectiva de los procesos de salud-enfermedad, en el artículo que nos presenta Ana Lidia García Peña se analiza la construcción de la subjetividad a través de la vivencia de la sífilis como una enfermedad crónica. Presenta, desde la noción de tecnologías del yo de Michel Foucault y el paradigma estético de Félix Guattari, un análisis de la subjetividad y sus formas de producción. En su texto nos conduce frente a dos modos de subjetivación contrapuestos. Aquel que partió de las estructuras de poder y que afianzaba la idea del cuerpo sifilítico como causante del desorden social, y el que nace del propio Rafael Montes de Oca que, como enfermo, reivindica su subjetividad a partir de una resignificación constante de su identidad y de sus objetivos en la vida, desafiando los dictados de la salud pública de la época, que prácticamente lo condenaban al ostracismo social.

García Peña explica cómo en medio de los cambios políticos, incluida una revolución de por medio y el desarrollo consecuente de una feroz campaña antisifilítica con tintes coactivos, el matrimonio de Rafael Montes de Oca con María Ríos Cárdenas fue decisivo para ambos, pues los dos construyeron una significación de su experiencia, con lo que la esposa-enfermera se convirtió en una exitosa feminista de los años treinta y él se transformó de un industrial a un comerciante, para finalmente convertirse en artista, con lo que cumplió su más grande anhelo, al tiempo que enfrentó la enfermedad que lo consumía en abierta confrontación con las políticas que veían al sifilítico como un degenerado al que le estaba vedado el matrimonio. De esta forma, la reflexividad, las experiencias y las identidades desarrolladas tanto por el sifilítico como por su mujer, en un binomio particular, son trabajadas como procesos de subjetivación dentro de un contexto de una fuerte presión sanitaria y cambios en la cultura de género.

Alicia Márquez, por su parte, analiza cómo algunas mujeres de clase media urbana construyen ciertas expectativas en relación con el parto fisio- 
lógico y, en ocasiones, en rechazo a la cesárea. Dichas expectativas, muchas veces influenciadas por los cursos psicoprofilácticos y los discursos de expertos de la biomedicina, dan lugar a un curso de acción que se ve interrumpido por una decisión tomada al término del embarazo, sobre todo por razones de seguridad. Es así como la noción de riesgo y el miedo al dolor afloran frente a los mandatos de la buena madre. En ocasiones, con sentimientos encontrados, algunas mujeres optan por la cesárea y, desde ahí, se ven obligadas a resignificar el sentido de su acción y sus vivencias.

En medio de este proceso, los discursos sobre el cuerpo sano vs. la medicalización desempeñarán un papel importante en la toma de decisiones y en la reflexividad de estas mujeres. En la tensión que provocan los discursos normativos sobre lo que es la manera "correcta" de vivir el embarazo y el parto, hay un espacio de subjetivación.

Rescatar las narrativas fue posible gracias a una aproximación cualitativa que aborda los dilemas experimentados por media docena de mujeres durante el proceso del embarazo y las decisiones que enfrentaron en relación con el parto, o bien ante una inminente cesárea. Las entrevistas pudieron realizarse mediante una página de Facebook sobre temas de maternidad, desde donde se convocó a dar testimonio sobre la experiencia del parto, lo que le permitió a Alicia Márquez entrar en contacto con quienes se sintieron llamadas, seguir su reflexividad y dar cuenta de cómo pudieron procesar lo subjetivamente vivido.

Desde la experiencia de la transgresión, el trabajo de Martha Santillán Esqueda revela el peso de la subjetividad para entender los procesos políticos y jurídicos que buscan transformar las relaciones sociales en el encuentro con sujetos sobre quienes se pretende incidir, no siempre con éxito. Así, mediante el análisis de dos casos de homicidio de mujeres que perdieron la vida a manos de sus parejas, Santillán analiza la construcción de la subjetividad masculina en el contexto del México posrevolucionario nacido de la Constitución de 1917, marco normativo que dio lugar en los años treinta a cambios jurídicos orientados a una significativa participación de las mujeres dentro y fuera del espacio doméstico y, por tanto, a una mayor autoridad en el plano familiar y en la definición de su propia vida.

La mayor autonomía que el texto constitucional estableció para que las mujeres se desenvolvieran en el ámbito público, ejemplificada en el derecho a trabajar e instruirse sin el consentimiento del padre o marido, o en la libertad para administrar su patrimonio y educar a sus hijos, disminuyó la 
dependencia de las mujeres respecto a los varones y con ello, abrió una puerta para desafiar el sistema patriarcal. De igual manera, la decidida intervención del Estado sobre las madres, a través de instituciones destinadas a configurar familias sanas física y mentalmente con el apoyo de especialistas (médicos, psiquiatras, pedagogos), brindó las herramientas para que, con la legitimidad de la ciencia en la mano, transformaran el rol tradicional de esposas sumisas. Pero este viejo modelo, ¿en verdad se estaba resquebrajando desde la perspectiva masculina?

En efecto, estos cambios se encaminaron a disminuir el control masculino sobre las mujeres. Así, el Código civil de 1931 ya no consideró lícito el homicidio por causa de infidelidad o en defensa del honor; $y$ algunos penalistas sostuvieron, con el ánimo de restringir la violencia de los varones hacia las mujeres, que el hombre podía controlar sus impulsos, incluso ante la afrenta de verse engañado por la esposa. Sin embargo, estas novedades de orden político y jurídico no encontraron su correlato social, pues no lograron modificar las relaciones entre los sexos sostenidas sobre las identidades de género; las estructuras patriarcales siguieron legitimando la violencia masculina como parte del derecho de los hombres sobre sus parejas para corregir conductas que constituyeran una afrenta al honor o a la reputación, como el adulterio. No obstante, la "rebeldía femenina" existió y fue vivida desde la masculinidad herida, sostiene Santillán. Mediante el análisis de los discursos psiquiátricos, criminológicos y penales, pero también de las concepciones sociales, muestra cómo los sujetos dotaron de significado a los homicidios cometidos, los justificaron como un deber dictado por el mandato de género, y sostuvieron su derecho a matar a la mujer que, sin ningún reparo, les confesaba su infidelidad. Pese a los cambios jurídicos, los procesos de subjetivación anclados en la violencia contra las mujeres se mantuvieron inalterados. Sin duda, una enseñanza para nuestros días.

Finalmente, José Antonio Maya González nos lleva a explorar el comportamiento criminal bajo otro ángulo, ya no desde la defensa que se prepara y razona para ser elevada al juez, sino ante un caso clínico donde las motivaciones inconscientes anidan junto a los deseos más profundos para arribar a una explicación psicológica del móvil del crimen. En ese México, que abandonaba las teorías degeneracionistas y eugenésicas que atribuían el comportamiento criminal a una fatal herencia, al alcoholismo o a la pobreza, y se adhería a las de corte psicológico y, en general, al vasto campo de la cultura (Ríos Molina, 2016), la película El hombre sin rostro (1950) de Juan Bustillo Oro, es analizada 
como un ejemplo del cine que buscó llegar al público interesado en el enigmático mundo de la locura criminal y de los sujetos peligrosos. Mostrar los móviles ocultos que podían arrastrar a un individuo a cometer un homicidio y dar cuenta del valor del psicoanálisis como una herramienta para descubrir ese mundo interior, encapsulado entre deseos reprimidos y sueños extraños, constituyen el propósito del cineasta que nos introduce en la subjetividad de un asesino serial de mujeres.

A través de las pesadillas que lo atormentan, un policía se remonta a las relaciones con su madre $y$, sin saberlo, va develando a su compañero de oficina, el perito legista que en el filme hace las veces de "médico-detective" y que lo recuesta en un sofá, su doble personalidad y los motivos que lo conducen cada noche a transmutarse en un psicópata sanguinario, aunque de día, como buen gendarme, se obstina infructuosamente en dar con el asesino sin rostro de sus sueños, que es él mismo. Tal conducta -oculta en una experiencia traumática- sólo se explica según el perito, por una relación materna sobrecargada de exigencias hacia el hijo, que provoca la emergencia del "deseo de fracasar", presente en su vida amorosa (incapaz de concretar un matrimonio) y profesional (incapaz de atrapar al asesino) y todo ello, para no contrariar a la madre.

Así, el psicoanálisis, partícipe en ese momento de las discusiones intelectuales sobre "lo mexicano", se muestra como una herramienta útil para la investigación criminológica, y el lenguaje cinematográfico como un medio para divulgar a un público amplio nociones básicas del campo psiquiátrico, que había incorporado el psicoanálisis a sus filas, en este caso, las tormentosas relaciones de una madre con su hijo como motor del crimen. Este propósito apenas se logró porque El hombre sin rostro estuvo muy poco tiempo en cartelera, pero queda como un esfuerzo muy importante por explicar la cuestión criminal desde la historia personal y la represión sexual, subjetividad develada gracias al recurso del método psicoanalítico que, a más de uno, dejó sobrecogido, como lo reportó la prensa en su momento.

El desarrollo del campo que recupera a los sujetos que han sido y son objeto tanto de las intervenciones institucionales como de los discursos sobre la salud, la enfermedad y la transgresión requiere mayor exploración. Hace falta descubrir a los actores desde su propia historia y desde la perspectiva de la subjetividad como una dimensión fundamental de la experiencia humana. La experiencia que constituye al sujeto, que le permite dar sentido a su relación con el mundo y consigo mismo. Esperamos que este dossier abra nuevos 
interrogantes y sea una invitación para continuar examinando esta temática desde diferentes perspectivas analíticas.

\section{LISTA DE REFERENCIAS}

Armus, D. (2000). La enfermedad en la historiografía de la América Latina moderna. Asclepio. Revista de Historia de la Medicina y de la Ciencia, 53(2), 41-60.

Giddens, A. (1987). The nation-state and violence. Vol. 2: A Contemporary Critique of Historical Materialism. California, Berkely y Los Ángeles: University of California Press.

Novella, E. J. (2013). Introducción: las ciencias de la mente y la historia de la subjetividad. Asclepio, 65(2), 12. DoI: http://dx.doi.org/10.3989/asclepio.2013.33

Thompson, E. P. (1981). Miseria de la teoría, Barcelona: Crítica.

Ortner, S. B. (2006). Anthropology and social theory. Culture, power and the acting subject. United States of America: Duke University Press.

Ríos Molina, A. (2016). Cómo prevenir la locura. Psiquiatría e higiene mental en México, 1934-1950. México: IIH-UnAM/Siglo XXI Editores.

Sewell, W. H, jr. (2005). Logics of history. Social theory and social transformation. Chicago: University of Chicago Press.

Scott, J. (2000). Los dominados y el arte de la resistencia. Discursos ocultos. México: Era. 